\title{
Psychological and Pedagogical Aspects of the Development of Integrative Readiness of Future Specialists for Professional Activity
}

\author{
Alina A. Predyk ${ }^{1}$ \\ Krystyna D. Shevchuk ${ }^{2}$ \\ Zoriana Z. Falynska ${ }^{3}$ (D) \\ Halyna B. Loik ${ }^{4}$ (D) \\ Petro M. Dziuba ${ }^{5}$
}

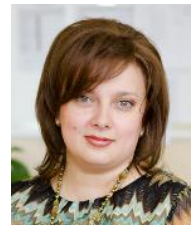

( Corresponding Author)

${ }^{1,2}$ Department of Pedagogy and Methodology of Primary Education, Faculty of Pedagogy, Psychology and Social Work, Yuriy Fedkovych Chernivtsi National University, Chernivtsi, Ukraine.

'Email:Predikalina@gmail.com Tel:+380506608893

'Email:docteurdeluniversite@yahoo.com Tel:380507385598

${ }^{s}$ Department of the Special Education and Social Work, Ivan Franko National University of Lviv, Lviv, Ukraine.

${ }^{5}$ Email:falynskazz@ukr.netTel: +380686077713

"Separate Division "Lviv branch of Kyiv National University of Culture and Arts", Lviv, Ukraine.

Email: gallojik@ukr.netTel: +380973884950

${ }^{5}$ General Military Subjects Department, National Academy of the State Border Guard Service of Ukraine named after Bohdan Khmelnytskyi, Khmelnytskyi, Ukraine.

Email:pit76@ukr.netTel:+380677270363

\section{Abstract}

The need to develop an integrative readiness of future specialists is a relevant scientific problem. The reasons for this could be based on the fact that that the specialists-to-be were expected to be involved in the fierce competition for vacancies and areas of activity, have modern information and communication tools, i.e. have an integrative readiness for professional activity. Institutions do not, however, have a single integration (interdisciplinary) framework for training, do not provide a comprehensive educational information, technical tools, strategies and technologies of education, reasoned psychological and pedagogical conditions. According to the author, the integrative readiness of future specialists for professional activity is a system-personality formation that reflects the unity of theoretical and managerial training and practical ability of students to comprehensively apply regulatory, socio-economic, psychological and pedagogical methods and technologies for solving different problems. This readiness reflects the unity of the motivational inclination of future specialists to professional activity and knowledge of practical technologies for solving a wide range of professional problems in personal and business interactions. The research methodology is based on the concept of key competence, which provides systematization, classification of significant problems, development of a matrix of significant problems, and determination of overall strategy, management technology of professional training development process. Students and teachers can use research materials can be used by in educational and practical activities; developers of content, organizational forms and methods of professional training to improve the practical component of curricula and standards of their development.

Keywords: Integrative readiness, Future specialists, Psychological, Pedagogical aspects, system-personality formation, concept of key competence, Interdisciplinary basis of professional training.

Citation | Alina A. Predyk; Krystyna D. Shevchuk; Zoriana Z. Falynska; Halyna B. Loik; Petro M. Dziuba (2020). Psychological and Pedagogical Aspects of the Development of Integrative Readiness of Future Specialists for Professional Activity. Journal of Education and e-Learning Research, 7(3): 263-269. History:

Received: 18 May 2020

Revised: 6 July 2020

Accepted: 5 August 2020

Published: 10 August 9090

Licensed: This work is licensed under a Creative Commons

Attribution 3.0 License (cc)

Publisher: Asian Online Journal Publishing Group
Acknowledgement: All authors contributed to the conception and design of the study.

Funding: This study received no specific financial support

Competing Interests: The authors declare that they have no conflict of interests.

Transparency: The authors confirm that the manuscript is an honest, accurate, and transparent account of the study was reported; that no vital features of the study have been omitted; and that any discrepancies from the study as planned have been explained.

Ethical: This study follows all ethical practices during writing. 
Contents

1. Introduction

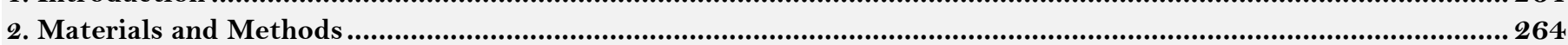

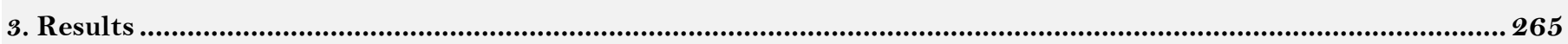

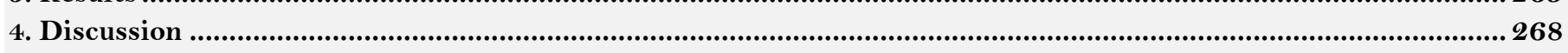

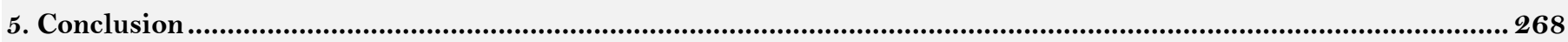

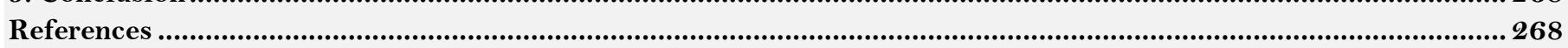

\section{Contribution of this paper to the literature}

This paper contributes to the existing research by solving the current problem of pedagogy of high school - the need to develop an integrative readiness of future specialists or professional activity (psychological and pedagogical aspects).

\section{Introduction}

The study of technologies for training future specialists for professional activities is associated with the development and justification of psychological and pedagogical aspects, which are one of the most important structural components of updating the content of education in modern theory and methodology of professional education (Markova, Sedykh, Tsyplakova, \& Polunin, 2018; Suvorov, 2011; Yusupova, Podgorecki, \& Markova, 2015). The update of the content of higher education is associated with the awareness of the need to develop competencies in future specialists which are in line with the current and future economic, business, cultural, and social relations (Jankovska, 2018). Such a competence is an integrative readiness for professional activity, which allows a specialist to perform several important functions (operational-mobile, information-communicative, intercultural, etc.) (McRae, 2015) necessary for the professional activity of a specialist in today's competitive environment. Professional training of future specialists in higher educational institutions raises various issues of improving educational and methodological programs, which provide for the development of readiness for work and the formation of professional competence (Bila, 2018; Polozenko, 2013; Zeleeva, Bykova, \& Varbanova, 2019). Integrative readiness for professional activity involves the formation of skills and abilities that are realized when performing official duties by a specialist in professional activity (Vedishenkova, Efimova, \& Ryabova, 2015).

Recent scientific research outlines the following main approaches to solving the problem of the development of the integrative readiness of future specialists for professional activity: psychophysiological, activity, personality, and personality-functional.

In terms of the psychophysiological approach, integrative readiness for professional activity is defined as a special psychophysiological state, which is manifested in the developed image of the structure of a certain professional activity and the focus of consciousness on its realization (Marchibayeva, Batima, Yessen, Bulatbayeva, \& Ergalieva, 2015). In the context of the functional approach, integrative readiness for professional activity is interpreted as the willingness and ability of future specialists to perform professional functions (Aguerrondo, 2009; Baltušite \& Katane, 2014). In the personality approach, integrative readiness for professional activity is considered as a complex personal formation containing a set of interrelated professionally significant qualities — ideological, moral and professional views and beliefs, professional orientation of mental processes, professional optimism, ability to adequately self-assess the results of their activities (Pérez-García, Morales-Ocaña, Martin-Romera, \& Garcia-Martinez, 2018). In the context of the personality-functional approach, integrative readiness is interpreted as a complex quality of future specialists, which is an organic unity of personal and functional components in their interdependence and relationship (Delz, 2018; Garavan \& McGuire, 2001; O'Sullivan, 2003).

The study of integrative readiness for professional activity in the psychological and pedagogical aspect of training a new type of specialists is of great importance for the theory and methods of higher professional education. The pedagogical literature (Colloff et al., 2017; Harr, Eichler, \& Renkl, 2015; Jaros, 2014; Katane \& Kalnina, 2010) provides almost no scientific justification for the development of integrative readiness of future specialists for work. The higher educational institutions do not have acceptable integrative (interdisciplinary) basis for training of specialists (Welch-Devine, Hardy, Brosius, \& Heynen, 2014). There is no satisfactory set of educational information and technical tools, strategies and technologies of education, reasonable psychological and pedagogical aspects of the formation and diagnosis of integrative readiness of future specialists for professional activity (Bila, 2018). This determined the objective, research methods, methodologies and strategies.

Thus, the objective of the study was to determine the content, structure, and features of the formation of integrative readiness of future specialists for professional activities based on the analysis of psychological and pedagogical aspects of the process of training future specialists for professional activities.

\section{Materials and Methods}

\subsection{Research Methods}

The paper used the methods needed to build a matrix of significant problems (questionnaires, testing, interviews, mathematical methods of processing survey results), as well as psychometric methods (mathematical interpretation of the degree of manifestation of accentuations of integrative readiness) and methods related to diagnosing learning effectiveness (pedagogical experiment, reflexive analysis of results).

\subsection{Research Methodology}

The research methodology was based on a systemic approach (taking into account many hierarchical elements, direct and feedback, structural integrity), and the concept of key competence (Khamel \& Prahalad, 2014) which involves the development of a matrix of significant problems and the identification of psychological and pedagogical aspects, general strategy, and the management of the development of integrative readiness. 


\subsection{Experimental Base of Research}

We conducted the study at Taras Shevchenko National University of Kyiv, Bohdan Khmelnytskyi Cherkasy National University, Poltava National V.G. Korolenko Pedagogical University, and the V.N. Karazin Kharkiv National University.

\subsection{Stages of Research}

The first stage (2018) was a study of the significant problems in the development of integrative readiness of future specialists for professional activity.

The second stage (2019) was to determine the set of psychological and pedagogical aspects of the development of integrative readiness of future specialists.

The third stage (2020) was a study of strategies and technologies for the development of integrative readiness of future specialists for professional activity.

\section{Results}

The empirical study of significant problems in the development of integrative readiness of future specialists for professional activity was based on the McRae's method McRae (2015).

At the first stage of the study (2018), we built a matrix of significant problems. Classification of significant (root, resultant, autonomous, etc.) problems and their analysis concluded that the elaboration and justification of psychological and pedagogical aspects of the development of integrative readiness of future specialists for professional activity should take into account:

- The current requirements for the training of future specialists.

- The contradictions that exist in the system of training specialists in higher educational institutions of Ukraine (Boden \& Borrego, 2011).

- The specifics of teaching a cycle of special subjects in higher educational institutions, which train specialists for professional activity.

- The features of training technologies for future specialists who are preparing for professional activity.

The traditional system of training future specialists introduces training courses and learning technologies in isolation from the real production process. They do not reflect the set of integrative duties that students must perform after graduating from higher educational institutions. As a rule, the low level of theoretical and practical training of graduates does not allow them to fill vacancies in modern companies or to participate in the competition for leading positions in these companies. In addition, there is a lack of sufficient organizational base to integrate the links between the graduating departments of higher educational institutions and basic enterprises, institutions, organizations in a professional field. There is a need to clarify the place and role of psychological and pedagogical aspects in the integrated structure of the educational process of training future specialists.

At the second stage of the study (2019), we identified psychological and pedagogical aspects of the formation of integrative readiness of future professionals for professional activity including:

- The content of the cycle of subjects studied for the Master's degree with scientific and practical components aimed at developing professional motives, interests, needs and goals of future professional activity.

- The rational and scientifically grounded selection of necessary and sufficient educational information, its prompt updating for the purpose of the development of integrative readiness for professional activity.

- The development and implementation of the academic subject Development of Integrative Readiness of Future Specialists and optional course Psychological and Pedagogical Readiness of Future Specialists for Professional Activity.

- Making changes to the integrated content of multimedia programs in order to achieve significant learning outcomes within the theoretical and practical training.

- Determining the volume of integrative knowledge, skills and methods of their implementation in multifunctional situations, as well as the effectiveness of their application.

Within the training for Master's degree, we found psychological and pedagogical aspects of the development of integrative readiness of future specialists for professional activity in the following directions:

- functional-target (task-target settings of polyfunctional professional-integrative training of future specialists);

- problem-cognitive (consistent formation of a multifunctional integrated portfolio, case sets of future specialists in the process of mastering the practice-oriented content of subjects of branch and university components of the curriculum, elective and optional courses); and,

- procedural and methodological (set of design, simulation-professional, contextual educational technologies; accumulation of experience and manifestations of various competencies of future specialists in the period of quasiprofessional activity and externship; development of the forms of research in professional activity), integrativeresultant (graduate's individual multifunctional integrative case set of a specialist; diagnostic tools for monitoring the level of the development of integrative readiness of future specialists for professional activity).

The second stage of the development of integrative readiness of future specialists for professional activity also provided:

1) The adaptation of the university component, elective and optional parts of the curriculum in relation to the needs of quality assurance of the system of integrative readiness for professional activity (author's elective subjects Development of Integrative Readiness of Future Specialists, Psychological and Pedagogical Readiness of Future Specialists for Professional Activity).

2) The gradual development of professional and multifunctional portfolio, case sets of future specialists in the periods of theoretical training and different types of practice.

3) The preparation of term papers and dissertations on topics that reflect the specifics of professional activity;

4) The participation of representatives of externship sites in work of jury of specialized competitions, competitions of social and economic projects on the development of the chosen professional sphere.

5) The implementation of individual student marketing, socio-economic projects. 
The study used the project activity types of students which are the most effective in the development of the integrative readiness of future specialists for professional activities such as:

- simulation-professional gaming projects (students in groups developed the content and scenario of a business game, which involved the distribution of roles - subjects of different types of personal and business interaction, fulfilment of a specific professional task in the form of a game, substantiation of professionally reasonable actions of a specialist).

- information-analytical projects (students mastered different methods of obtaining various professionally significant information and methods of its processing: analysis of legal, financial and economic documents in the professional sphere, computer databases, scientific, methodical, monographic literature, interviews with practicing experts, analysis of materials of specialized professional journals).

- specialized practice-oriented projects (substantiation and development of a plan for the implementation of a specific project; during the presentation of the project they show methods of its implementation, and practitioners give an external expert assessment of the project).

The whole experimental process used modern information technologies and a multimedia program, as their technical capabilities provided feedback between the software and students. The multimedia environment acted as a full-fledged "partner" of the dialogue, which helped the educational information take various forms (interactive text links, formulas, illustrations of technological processes). Different technical capabilities of the multimedia program allowed future specialists to independently model the learning and production process based on their own psychological features, which introduced a game in learning and increased motivation to learn. A fixed algorithm of the structure of educational material, presented with the help of a multimedia program, directed students in solving educational and professional problems and achieving the goal of learning.

\subsection{Pedagogical Experiment}

We divided the students into experimental (EG) and control groups (CG) for the purpose of comparative analysis of traditional teaching and realization of psychological and pedagogical aspects of the development of integrative readiness of future specialists for professional activity. We determined homogeneity and uniformity of experimental and control groups in the experiment as follows: the mean and the levels of all components (accentuations) of integrative readiness of future specialists at the stage of input control in EG and CG students were close in values. One of the important indicators of the quality of the development of integrative readiness of future specialists for professional activity is its level. In terms of content, integrative readiness should be diagnosed based on pronounced accentuations such as:

- Motivational - focus on mastering the chosen profession.

- Cognitive - knowledge and understanding of the peculiarities of professional activity.

- Praxeological - the use of knowledge in professional activities.

- Personality — personality self-realization as future specialists.

The experiment on the diagnosis of accentuations associated with the manifestation of integrated readiness for professional activity involved 258 students with the results presented in Table 1, 2, and Figure 1.

Table-1. Levels of the manifestation of accentuations of integrative readiness of future specialists for the experiment (in \%)

\begin{tabular}{|c|c|c|c|c|c|c|c|c|c|}
\hline \multirow{3}{*}{\multicolumn{2}{|c|}{$\begin{array}{l}\text { Components } \\
\text { readiness }\end{array}$}} & \multicolumn{8}{|c|}{$\begin{array}{l}\text { Numerical indicators by the levels of the development of the components and } \\
\text { integrative readiness of future specialists to practice the profession }\end{array}$} \\
\hline & & \multicolumn{2}{|c|}{ High } & \multicolumn{2}{|c|}{ Sufficient } & \multicolumn{2}{|c|}{ Satisfactory } & \multicolumn{2}{|c|}{ Low } \\
\hline & & $\mathrm{NS}$ & $\%$ & $\mathrm{NS}$ & $\%$ & $\mathrm{NS}$ & $\%$ & $\mathrm{NS}$ & $\%$ \\
\hline Motivational & & 36 & 13.95 & 94 & 36.43 & 93 & 36.05 & 35 & 13.57 \\
\hline Cognitive & & 19 & 7.36 & 75 & 29.07 & 131 & 50.78 & 33 & 12.79 \\
\hline Praxeological & & 26 & 10.08 & 78 & 30.23 & 112 & 43.41 & 42 & 16.28 \\
\hline Reflexive & & 29 & 11.24 & 90 & 34.88 & 108 & 41.86 & 31 & 12.02 \\
\hline General readiness & & 29 & 11.24 & 83 & 32.17 & 112 & 43.41 & 34 & 13.18 \\
\hline
\end{tabular}

Table-2. Levels of manifestation of accentuations of integrative readiness of future specialists after the experiment (in\%).

\begin{tabular}{|c|c|c|c|c|c|c|c|c|c|c|}
\hline \multirow{3}{*}{$\begin{array}{l}\text { Groups and number } \\
\text { of students }\end{array}$} & \multirow{3}{*}{$\begin{array}{l}\text { Stages of } \\
\text { control }\end{array}$} & \multicolumn{9}{|c|}{$\begin{array}{c}\text { Numerical indicators of integrated readiness of students for } \\
\text { professional activity }\end{array}$} \\
\hline & & \multicolumn{2}{|c|}{ High } & \multicolumn{2}{|c|}{ Sufficient } & \multicolumn{2}{|c|}{ Satisfactory } & \multicolumn{2}{|c|}{ Low } & \multirow{2}{*}{ MV } \\
\hline & & NS & $\%$ & NS & $\%$ & NS & $\%$ & NS & $\%$ & \\
\hline CG-69 s. & IC & 8 & 11.60 & 22 & 31.88 & 30 & 43.48 & 9 & 13.04 & 3.42 \\
\hline $\mathrm{CG}-67 \mathrm{~s}$. & $\mathrm{FC}$ & 9 & 13.43 & 26 & 38.81 & 28 & 41.79 & 4 & 5.97 & 3.60 \\
\hline EG-68 s. & IC & 6 & 8.82 & 23 & 33.82 & 30 & 44.12 & 9 & 13.24 & 3.38 \\
\hline EG-68 s. & $\mathrm{FC}$ & 34 & 50.0 & 7 & 10.29 & 27 & 39.71 & $\mathrm{O}$ & $\mathrm{O}$ & 4.10 \\
\hline
\end{tabular}

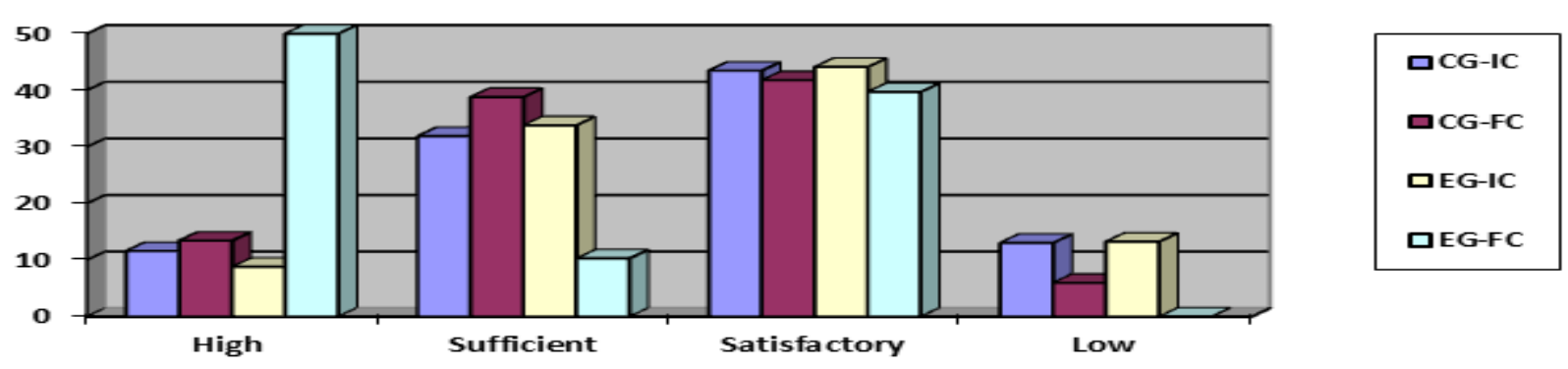

Figure-1. The level of accentuation of integrative readiness of future specialists after the experiment (in \%). 
Based on the generalization of the results of the pre-experimental stage of the study, we analysed the state of integrative readiness of future specialists for professional activity, which varies within the following limits:

1) High level is inherent in $7.36-13.95 \%$.

2) A sufficient level is inherent in $29.07-36.43 \%$ of students.

3) 36.05 to $50.78 \%$ of future specialists is characterized by a satisfactory level.

4) 12.02 to $16.28 \%$ of students showed a low level.

We applied different procedures to mathematically measure accentuation such as:

- In the diagnosis of motives associated with professional activities - motivational and creative assignments of professionally-oriented type.

- In the diagnosis of skills characteristic of integrated readiness - logical and practical tasks of professionallyoriented type.

- In the diagnosis of cognitive processes of the development of integrated readiness - test assignments of a creative nature.

- To diagnose skills related to self-realization of an individual - cases with real life and professional situations that characterize the integrated readiness in the real professional activity.

According to the data in Table 1, and 2, and Figure 1, there was a positive trend in accentuation. The number of future specialists with a high level of personality-oriented knowledge, skills and abilities in the control groups increased by $1.83 \%$, and in EG - by $41.18 \%$, which was $39.35 \%$ more than in CG and $41.18 \%$ more than before the experiment. The number of students who have a sufficient level of integrated readiness increased by $6.93 \%$, and in EG there was a decrease of $23.53 \%$ based on a significant increase in the number of students with a high level. There was a decrease in the number of students with a satisfactory level of integrated readiness of future specialists in CG by $1.69 \%$, and in EG - 4.41\%, which was $2.72 \%$ more than in CG students and $4.41 \%$ less than before the experiment. After the experiment, there were no EG students with a low level, and the number of students in the CG decreased by $7.07 \%$, which was $6.17 \%$ more than in the control groups.

We applied statistical methods of processing the data of the pedagogical experiment to prove the reliability of the results and determine the reliability of the experimental study. To test the hypothesis of the study, we compared the variances, and determined the F-test according to the Kyverialg's method Kyverialg (1980) (Formula $1)$ :

$$
F_{e m p}=\frac{\sigma_{1}^{2}}{\sigma_{2}^{2}}
$$

where ${\sigma_{1}}^{2}$ - greater variance; $\sigma_{2}{ }^{2}-$ smaller variance.

We determined variances at the stages of input and final control, as well as the establishment of values of the levels of integrated readiness of future specialists for professional activity.

We calculated the variances using Formula 2:

$$
\sigma^{2}=\frac{\sum f\left(x_{i}-\bar{x}\right)^{2}}{N}
$$

where $f$ - the number of students who showed a certain level of readiness for professional activity, which is expressed in values of $5,4,3,2$ points;

$\left(x_{i}-\bar{x}\right)$ - the difference between the value of the level and the mean value (MV);

$\mathrm{N}$ - the number of students in those categories of groups (control or experimental), where the variance is calculated.

To verify the reliability of the obtained results, we compared the indicators of the empirical F-test of control $\left(\mathrm{F}_{\text {enp }}-\mathrm{CG}\right)$ and experimental groups $\left(\mathrm{F}_{\text {ent }}-\mathrm{EG}\right)$ with the indicators of the theoretical $\mathrm{F}$-test $\left(\mathrm{F}_{\text {crit }}\right)$, their values are provided in the standard table (Kyverialg, 1980).

\begin{tabular}{|c|c|c|c|c|}
\hline \multirow[b]{2}{*}{ Components of readiness } & \multirow[b]{2}{*}{ Groups and stage of control } & \multicolumn{3}{|c|}{ Values for determining F-test } \\
\hline & & $\sum f\left(x_{i}-\bar{x}\right)^{2}$ & $\sigma^{2}$ & $\mathbf{F}_{e m p}$ \\
\hline \multirow{4}{*}{ Motivational } & $\mathrm{CG}-\mathrm{IC}$ & 55.21739 & 0.80025 & \multirow{2}{*}{0.84} \\
\hline & CG-FC & 45.10448 & 0.67320 & \\
\hline & EG-IC & 42.98529 & 0.63214 & \\
\hline & EG-FC & 57.80882 & 0.85013 & 1.34 \\
\hline \multirow{4}{*}{ Cognitive } & $\mathrm{CG}-\mathrm{IC}$ & 42.60869 & 0.61751 & \multirow{2}{*}{1.03} \\
\hline & CG-FC & 42.65672 & 0.63667 & \\
\hline & EG-IC & 41.69118 & 0.61311 & \multirow{4}{*}{0.84} \\
\hline & EG-FC & 54.98529 & 0.80861 & \\
\hline \multirow{4}{*}{ Praxiological } & $\mathrm{CG}-\mathrm{IC}$ & 51.65217 & 0.74858 & \\
\hline & CG-FC & 42.11940 & 0.62865 & \\
\hline & EG-IC & 43.69118 & 0.64252 & \multirow{2}{*}{1.35} \\
\hline & EG-FC & 58.86765 & 0.86570 & \\
\hline \multirow{4}{*}{ Reflective } & CG-IC & 49.15942 & 0.71246 & \multirow{2}{*}{0.88} \\
\hline & CG-FC & 42.11940 & 0.62865 & \\
\hline & EG-IC & 46.94118 & 0.69031 & \multirow{4}{*}{0.85} \\
\hline & EG-FC & 61.80882 & 0.90895 & \\
\hline \multirow{4}{*}{ General readiness } & CG-IC & 50.81159 & 0.73640 & \\
\hline & CG-FC & 42.11940 & 0.62865 & \\
\hline & EG-IC & 46.05882 & 0.67734 & \multirow{2}{*}{1.31} \\
\hline & EG-FC & 60.27941 & 0.88646 & \\
\hline
\end{tabular}

Table-3. The results of the calculation of variances to determine the empirical F-test. 
Provided that the number of degrees of freedom (number of students in the group minus 1) will be in the range from 24 to infinity and from 60 to 120 (as in our study): $69-1=68 ; 68-1=67 ; 67-1=66$ ), the value of $\mathrm{F}_{\text {crit }}$ for $\mathrm{CG}$ and EG shall be within the range of $1.7 \ldots 1.3$.

Table 3 shows calculations of variances in order to determine the empirical F-test for each component of the integrated readiness of future specialists for professional activities and the overall results of the study and indicates their reliability.

Comparative analysis of the empirical value of the F-test in the control and experimental groups with the determined limits of $\mathrm{F}_{\text {crit }} 1.8$ - 1.3 for all components showed that $\mathrm{F}_{\text {emp }}-\mathrm{KG}$ with a value from 0.84 to 1.03 goes beyond these limits, and $\mathrm{F}_{\text {emp }}$-EG with a score from 1.31 to 1.35 confirms the reliability of the results.

We assessed the levels of accentuation in the development of integrative readiness of future specialists for professional activity (practical lessons in-class and during externship) based on psychometric methods (a set of tests and assignments). The experts summarized the results of completed tests and assignments using mathematical analysis.

\section{Discussion}

The above results related to the issues of this study and were in line with the literature that covers the best strategies for developing the readiness of future specialists for professional activity (Hyman-Shurland, 2016; Schwonke et al., 2013; Trede, 2012). The results of the study, which were consistent with previous studies, showed that the quality of intervention in professional education was improved through the use of multifunctional integrated portfolio, case sets, a set of design, simulation-professional, contextual educational technologies, individual multifunctional integrative case set of a specialist. This is due to the fact (Sorokoumova, Nikonova, Sharonov, Suvorova, \& Sorokoumova, 2016) that students work better in situations close to professional activity on the basis of acquired theoretical information and the development of practical skills. This is the basis for assessing the readiness of graduate or Master's students for professional activity.

The study was consistent with scientific research (Koehler, Mishra, \& Cain, 2013; Ross \& Millot, 2016; WelchDevine et al., 2014). The scholars stated that in modern conditions the content of the university component of the curriculum is actualized on the basis of professional applied approach to stimulate students' mastery of the system of competencies, taking into account the specifics and variability of professional activities of future specialists, current and future market needs.

This study was also consistent with the findings of studies (Duong, 2014; Keengwe \& Kang, 2013; Roth, 2010) which demonstrated the importance of practice-oriented integrative education of future specialists through interdisciplinary links of special subjects based on identification and scientific comprehension of typical situations of professional activity of future specialists. The study provides a new understanding of the psychological and pedagogical aspects of the development of integrative readiness of future specialists in the traditional professional training and with the involvement of employers.

Issues related to finding the optimal combination of psychological and pedagogical aspects with digital technologies and resources remain debatable. Online education is now perceived as an alternative to traditional education; it allows you to get a diploma remotely, sometimes without the proper level of integrative readiness. This adversely affects the quality of training of future specialists for professional activities. A reasonable combination of personality, distance and professional communication is needed. This requires a broader pedagogical study.

The results of the study can be challenged based on the number of students selected, the duration of the experiment and the tools used to obtain statistics. In addition, the study assessed the actual behaviour of respondents, rather than their attitude to the psychological and pedagogical aspects of the development of integrative readiness for professional activity. The results of the study rely on only one group of selected students. We can argue that there was no alternative explanation for the results.

\section{Conclusion}

Current conditions attribute special importance to such a concept as the integrative nature of a specialist, which involves a specialist's ability to apply a limited volume of professionally oriented knowledge on an unlimited number of problems in various spheres of human life and ensure further mobility of skills. At the present stage of HR development, it is necessary that the system of professional education provides future specialists with such a set of knowledge, skills, competencies that will allow a significant change in the content of their professional activity.

Thus, the realization of selected psychological and pedagogical aspects of the development of integrative readiness of future specialists for professional activities scientifically and methodologically provides interdisciplinary links, content and logical unity of different special subjects; the relationship between theoretical training courses and various workshops, types of industrial practice and quasi-professional activities. The considered aspects provide acquiring the system of practical technologies of professional activity: technologies of legal support of vital activity of different enterprises, institutions, organizations; technologies of information and telecommunication support of professional activity; marketing and monitoring technologies.

The set of measures ensured the development of integrative readiness of future specialists for professional activity: they began to actively use modern information and communication tools, better orient themselves in the professional field, there was a single integration (interdisciplinary) basis for training masters, and new effective strategies and technologies for future specialists.

Further research could be undertaken on the development of forms of interaction between the university and employers to improve the professional and practical skills of future specialists; development of students' selfeducational culture while mastering the technologies of professional activity; and the training of teachers of higher educational institutions to work on the formation of integrative readiness for professional activity.

\section{References}

Aguerrondo, I. (2009). Complex knowledge and education competences. Geneva, Switzerland: International Bureau of Education. 
Baltušīte, R., \& Katane, I. (2014). The structural model of the pedagogy students' readiness for professional activities in the educational environment, in: V. Dišlere (Ed.). Paper presented at the Proceedings of the International Scientific Conference: Rural Environment. Education. Personality. Jelgava, Latvia: LLU.

Bila, O. (2018). The preparation of future specialists of socionomical field to projecting professional activity. Journal of Danubian Studies and Research, 8(2), 144-149.

Boden, D., \& Borrego, M. (2011). Academic departments and related organizational barriers to interdisciplinary research. Higher Education in Review, 8, 41-64.

Colloff, M. J., Martín-López, B., Lavorel, S., Locatelli, B., Gorddard, R., Longaretti, P.-Y., . . Coreau, A. (2017). An integrative research framework for enabling transformative adaptation. Environmental Science $\mathcal{E}^{2}$ Policy, 68, 87-96. Available at: https://doi.org/10.1016/j.envsci.2016.11.007.

Delz, S. (2018). Towards an integrative approach to spatial transformation. International Development Policy, 10, 188-212. Available at: https://doi.org/10.4000/poldev.2695.

Duong, T. M. (2014). An investigation into effects of role-play in an EFL speaking course. Global Journal of Foreign Language Teaching, 4(2), $81-91$.

Garavan, T. N., \& McGuire, D. (2001). Competencies and workplace learning: Some reflections on the rhetoric and the reality. Journal of Workplace Learning, 13(4), 144-164. Available at: http://doi.org/10.1108/13665620110391097.

Harr, N., Eichler, A., \& Renkl, A. (2015). Integrated learning: Ways of fostering the applicability of teachers' pedagogical and psychological knowledge. Frontiers in Psychology, 6, 738-752. Available at: https://doi.org/10.3389/fpsyg.2015.00738.

Hyman-Shurland, Y. (2016). The merits of trust in transformational leadership [Doctoral Dissertation]. Walden University, Minneapolis, MN.

Jankovska, A. (2018). Development trends in pedagogical and psychological sciences: The experience of countries of Eastern Europe and prospects of Ukraine: Monograph. Riga, Latvia: Baltija Publishing.

Jaros, M. (2014). Leadership and methodology challenges in higher education: Integrating personal development, skills and competences in the space of digital systems. Global Journal of Information Technology, 4(1), 1-6.

Katane, I., \& Kalniņa, I. (2010). Competitiveness development of students' personality in environment of non-formal commercial education. Jelgava, Latvia: LLU.

Keengwe, J., \& Kang, J.-J. (2013). A triangular prism model: Using activity theory to examine online learning communities. Education and Information Technologies, $18(1)$, 85-93. Available at: http://doi.org/10.1007/s10639-011-9178-4.

Khamel, G., \& Prahalad, K. (2014). Competing for the future. Creating tomorrow's markets. Moscow, Russia: Olimp-Biznes.

Koehler, M. J., Mishra, P., \& Cain, W. (2013). What is technological pedagogical content knowledge (TPACK)? Journal of Educational Psychology, 193(3), 13-19. Available at: https://doi.org/10.1177/002205741319300303.

Kyverialg, A. A. (1980). Research methods in professional pedagogy. Tallinn, Estonia: Valgus.

Marchibayeva, U., Batima, T., Yessen, O., Bulatbayeva, A., \& Ergalieva, A. (2015). Psychological aspects of formation the professional competence of the future specialists. Procedia-Social and Behavioral Sciences, 185, 276-280. Available at: https://doi.org/10.1016/j.sbspro.2015.03.365.

Markova, S. M., Sedykh, E. P., Tsyplakova, S. A., \& Polunin, V. Y. (2018). Perspective trends of development of professional pedagogics as a science. Advances in Intelligent Systems and Computing, 622, 129-135.

McRae, N. (2015). Exploring conditions for transformative learning in work-integrated education. Asia-Pacific Journal of Cooperative Education, 16(2), 137-144.

O'Sullivan, E. (2003). Bringing a perspective of transformative learning to globalized consumption. International Journal of Consumer Studies, 27(4), 326-330. Available at: https://doi.org/10.1046/j.1470-6431.2003.00327.x.

Pérez-García, P., Morales-Ocaña, A., Martin-Romera, A., \& Garcia-Martinez, I. (2018). Initial training of future education professionals: Are you prepared for inclusion? Paper ECER (2018). Available at: http://dx.doi.org/10.2139/ssrn.3253665.

Polozenko, O. (2013). Professio-graphic approach to psychological preparation of future specialists of agrarian sphere to professional activity. Education - Technology - Computer Science, 4(1), 321-325.

Ross, S. M., \& Millot, D. (2016). Short cycle studies as an emerging paradigm for developing and evaluating educational technology products: The New York city iZone initiative. World Journal on Educational Technology, 6(3), 279-290.

Roth, W. M. (2010). Toward a dynamic understanding of mind, culture, activity and life: Difference-in-itself as the source of change. Mind, Culture and Activity, $17(2), 203-211$.

Schwonke, R., Ertelt, A., Otieno, C., Renkl, A., Aleven, V., \& Salden, R. J. (2013). Metacognitive support promotes an effective use of instructional resources in intelligent tutoring. Learning and Instruction, 23, 136-150. Available at: http://dx.doi.org/10.1016/j.learninstruc.2012.08.003.

Sorokoumova, S. N., Nikonova, E. I., Sharonov, I. A., Suvorova, O. V., \& Sorokoumova, E. A. (2016). Modern functions of a tex tbook on social sciences and humanities as an informational management tool of University education. International Journal of Environmental and Science Education, 11(10), 3764-3774.

Suvorov, O. (2011). The model of a polysubject communicative-cognitive environment of an educational institution. University Bulletin (State University of Management), 14, 127-131.

Trede, F. (2012). Role of work-integrated learning in developing professionalism and professional identity. International Journal of WorkIntegrated Learning, 13(3), 159-167.

Vedishenkova, M. V., Efimova, E. V., \& Ryabova, E. V. (2015). Student's research work as the condition of continuity of general and professional education. International Journal of Environmental and Science Education, 10(4), 533-542. Available at: https://doi.org/10.12973/ijese.2015.267a.

Welch-Devine, M., Hardy, D., Brosius, J. P., \& Heynen, N. (2014). A pedagogical model for integrative training in conservation and sustainability. Ecology and Society, 19(2), 10-25. Available at: http://dx.doi.org/10.5751/ES-06197-190210.

Yusupova, G. F., Podgorecki, J., \& Markova, N. G. (2015). Educating young people in multicultural educational environment of higher education institution. International Journal of Environmental and Science Education, 10(4), 561-570. Available at: https://doi.org/10.12973/ijese.2015.270a.

Zeleeva, V., Bykova, S., \& Varbanova, S. (2019). Psychological and pedagogical support for students' adaptation to learning activity in high science school. International Journal of Environmental $\mathcal{E}^{\circ}$ Science Education, 11(3), 151-161. Available at: https://doi.org/10.12973/ijese.2016.299a. 